\title{
EFFECT OF NANO-SILVER IRRIGATING SOLUTION ON POST-OPERATIVE PAIN FOLLOWING SINGLE VISIT ENDODONTIC THERAPY: A PROSPECTIVE RANDOMIZED CLINICAL TRIAL
}

\author{
Alaa A El-Baz ${ }^{*}$ and Geraldine M. Ahmed*
}

\begin{abstract}
Objective: The purpose of this study was to compare the effect of nano-silver (Nanotech Egypt for photo Electronics, Cairo, Egypt) irrigating solution versus sodium hypochlorite on postoperative pain after single- visit endodontic therapy.

Methods: A randomized controlled clinical trial was designed and carried out in the endodontic department at Cairo University. Fifty healthy patients with asymptomatic necrotic teeth that were scheduled for non-surgical root canal treatment were enrolled. Single- visit root canal treatment was performed using ProTaper Universal (PTU; Dentsply Maillefer, Ballaigues, Switzerland) rotary files and for irrigation $\mathrm{NaOCl} 5.25 \%$ (Egyptian Company for household products under license of Clorox. Co. Cairo, Egypt) (control group, $\mathrm{n}=25$ ) and nano-silver irrigating solution (intervention group, $n=25$ ) were used. After obturation, post-operative pain was assessed using a visual analogue scale (VAS) after 4, 24, and 48 hours. Chi-square test was used to compare VAS values between tested groups within each follow- up period and Wilcoxon signed rank test was used for within group comparisons over time.
\end{abstract}

Results: Insignificant differences between $\mathrm{NaOCl}$ group and nano-silver group were found in pain scores for each follow-up period. The pain score decreased significantly after 24 hours $(\mathrm{p}=0.003)$ and after 48 hours $(\mathrm{p}=0.001)$ in intervention group. Control group showed similar results were the pain score decreased significantly after 24 hours $(\mathrm{p}=0.008)$ and after 48 hours $(\mathrm{p}=0.001)$.

Conclusion: Both tested irrigants were associated with a decrease of postoperative pain over time, in patients undergoing single-visit endodontic treatment with necrotic pulps. There was no statistical significant difference between both groups.

KEYWORDS: Sodium Hypochlorite, nano-silver irrigation, Pain, Postoperative, single-visit

* Associate Professor, Endodontic Department, Faculty of Oral and Dental Medicine, Cairo University 


\section{INTRODUCTION}

Postoperative pain is an undesired yet common sensation after root canal treatment, since its incidence was reported to range from $3 \%$ to $58 \%{ }^{(1)}$. Postoperative pain could be due to microbial factors, to the effects of chemical mediators, to phenomena related to the immune system, to cyclic nucleotide changes, to psychological factors, and to changes in the local adaptation ${ }^{(2)}$.

Mechanical instrumentation and irrigation are used aiming at removing vital and necrotic remnants of pulp tissue, debris, microbiota and their byproducts from the root canal system. ${ }^{(3)}$ Even with the introduction of modern rotary instrumentation, complete debridement of canals is reported to be very difficult to achieve. Some authors, using micro-computed tomography scanning, have shown that most of the area of main root canal walls remained untouched by the mechanical instrumentation ${ }^{(4)}$. These areas can harbor debris of tissues, microbes, and their by-products ${ }^{(5)}$, and this can result in reinfection or persistent periradicular inflammation $^{(6)}$. This aspect emphasizes the importance of other means of cleaning and disinfecting all areas of the root canal system ${ }^{(7)}$.

No unique irrigant solution can meet all the requirements of an ideal irrigant ${ }^{(8)}$. Several studies have proven the effectiveness of the use of solutions of sodium hypochlorite $(\mathrm{NaOCl})$ in addition to mechanical cleaning and shaping ${ }^{(8,9)}$. $\mathrm{NaOCl}$ is highly effective in tissue dissolution and in the removal of bacterial biofilm because of its ability to hydrolyze and oxidize cell proteins, its release of free chlorine, and its $\mathrm{pH}$ of 11 to $12^{(10)}$. Since tissue dissolution is mandatory for antimicrobial action, $\mathrm{NaOCl}$ is the most used antimicrobial irrigant solution in root canal therapy. On the other hand, $\mathrm{NaOCl}$ also possesses several disadvantages as, significant toxicity when extruded from the root canal system, disagreeable smell and taste, risk of bleaching clothes, and corrosion of metal objects.
Most importantly, $\mathrm{NaOCl}$ is not bactericidal for all species of bacteria, it is ineffective in removing the smear layer, and its action results in changes in dentin physical properties ${ }^{(11)}$.There is an associated risk for $\mathrm{NaOCl}$ accidental injection into the periapical tissues through the apical constriction of the root canal, leading to severe, painful postoperative complications. ${ }^{(12)}$ Therefore, many irrigating devices are being developed to provide a safe delivery system thus preventing periapical damage and thereby reducing postoperative pain. ${ }^{(13)}$

Nano-silver has a bactericidal effect and was used as irrigating solution due to its low surface tension, and to the nanoparticles that can penetrate the smallest fissures and dental tubules of the root canal system. In this way, even the bacteria residing in the fissures in spore-form after root canal treatment could be reached by the irrigating solution. The nano-silver interacts with multiple targets in the microbial cell, such as cell membrane, enzymes and plasmids, simultaneously providing the bacteria least capacity to gain resistance. ${ }^{(14)}$.The use of solutions with nano-silver has been proposed in root canal therapy due to their inhibitory effect on bacteria. Nano-silver has an affinity to the abundant sulfur-containing amino acids inside and outside the bacterial cell membrane which in turn affects the bacterial cell viability ${ }^{(15)}$. Moreover, nano-silver has been recommended as an alternative root canal irrigating solution not only for its strong bactericidal potential but also for its biocompatibility, especially in lower concentration ${ }^{(16-17)}$.

The aim of this study was to compare the postoperative pain after using nano-silver versus $\mathrm{NaOCl}$ irrigation after single visit root canal treatment in asymptomatic necrotic teeth.

\section{MATERIALS AND METHODS}

The outline of this study was approved by the Ethical Committee of Cairo University. This study was performed over a 6-month period spanning from February to June 2016. 
All the patients who participated in this study were informed about the treatment protocols, benefits, risks, treatment alternatives, and signed an informed consent.

\section{Sample size}

Sample size calculation was based on an error of alpha $=0.05$ and a power of $80 \%$, and a significance level of $5 \%$ indicating an ideal sample size of 44 subjects. This number has been increased to a total sample size of 50 , to allow for losses of around $15 \%$.

\section{Randomization and blinding}

The sequence generation was done for the patient's numbers (from 1 to 50) using computer sequence generation (http://www.random.org/) which gave a table for group A and group B with randomized patients' numbers (25 number in each group). Group A (control group) was the sodium hypochlorite group while group B (intervention group) was the nano-silver group. For the allocation concealment mechanism, 50 papers (each was eight folded) with a number from 1 to 50 were placed inside opaque envelopes. Each patient picked up an envelope before the treatment. The number in the envelope determined which irrigation solution was to be used for that patient according the table generated by the computer. The operator knew which irrigating solution will be used.

\section{Trial design}

The study was reported following the guidelines provided in the Consolidated Standards for Reporting Clinical Trials (CONSORT) statement (18). The present was a parallel-group randomized controlled clinical trial with an allocation ratio of $1: 1$.

\section{Participants}

The inclusion criteria were:

- 18 years old or older

Single rooted teeth
- Subjects without any relative or absolute contraindication to endodontic treatment as tooth hypermobility (grade III), presence of untreatable longitudinal fracture

- Clinical diagnosis of asymptomatic pulp necrosis: non-responsive to thermal pulp testing. No pain to percussion or radiographic evidence of osseous breakdown.

- Patients who were able to sign an informed consent form

- Subjects classified as ASA-1 following the classification proposed by the American Society of Anesthesiologists.

The exclusion criteria were:

- Patients taking analgesics or anti-inflammatory drugs in the seven days before intervention

- Patients with vital teeth, apical periodontitis, periapical radiolucency, retreatments, root resorption, immature/open apex, or a root canal in which the is no patency to the apical foramen.

\section{Interventions}

All subjects were treated in the out-patient endodontic clinic, Faculty of Oral and Dental Medicine, Cairo University, Cairo, Egypt. Data were collected and analyzed in the same Department. All patients were treated by a single experienced operator.

Patients were anesthetized using nerve block local anesthesia or infiltration local anesthesia with Mepivacaine 2\% + epinephrine 1:100.000 (Carpule Mepecaine-L, Alexandria Company for Pharmaceuticals and Chemical Industries, Alexandria, Egypt) according to the tooth location in mandibular or maxillary arch respectively. After removal of caries-affected tissue, access cavity was created after rubber dam application. Working length was determined using an electronic apex locator (Root ZX, J.Morita USA, Irvine, CA.) then 
confirmed with intraoral periapical radiograph, to be 0.5-1 mm, shorter than radiographic apex. Cleaning and shaping was done using crown down preparation technique with the ProTaper Universal (PTU; Dentsply Maillefer, Ballaigues, Switzerland) in an endodontic motor according to the manufacturer instructions (X-Smart, Dentsply Tulsa, Salzburg, Austria.) Glyde File Prep (Dentsply, Maillefer, Ballaigues, Switzerland) was used as a lubricant during mechanical preparation. Depending on each tooth the final instrumentation size was ProTaper F3 or F4. All teeth received the same volume of irrigant.

Control group (A): irrigated with $5.25 \% \mathrm{NaOCl}$ (Egyptian Company for household products under license of Clorox. Co. Cairo, Egypt) $3 \mathrm{ml}$ between each file using 30-gauge Max-i-Probe syringe that was placed down the canal, $2 \mathrm{~mm}$ short of the apex.

Intervention group (B): irrigated with nanosilver based irrigant $3 \mathrm{ml}$ between each file (Yellow solution of citrate functionalized silver nanoparticles dispersed in water of concentration $1 \mathrm{mM} \mathrm{Ag} 1+$ $(109 \mu \mathrm{g} / \mathrm{ml})$ and of average size $20 \mathrm{~nm}$ and spherical in shape placed in dark bottle to avoid oxidation of its silver content with light (Nanotech Egypt for photo Electronics, Cairo, Egypt)

All canals were irrigated with $5 \mathrm{~mL}$ normal saline then dried with sterile paper points and obturation was carried out using the single cone technique using protaper guttapercha cones and resin sealer (ADSEAL, META BIOMED CO., LTD, Cheongju, Korea) with spreader (Mani, INC, Utsunomiya Tochigi, Japan) size according to master cone size, its depth short $2 \mathrm{~mm}$ of the working length. After obturation, a cotton pellet was placed in the pulp chamber and the access cavity was closed with a temporary filling to avoid coronal leakage (MDTemp, META BIOMED CO., LTD, Cheongju, Korea). As it was prescribed in other studies with the same aim of the present all patients received eight tablets of ibuprofen $200 \mathrm{mg}$ to take only one tablet if needed within 0-4 hour time interval after the treatment and then one tablet every eight hour in the event of pain $(3,7,11,13)$.

\section{Outcomes}

Following the treatment, each patient received a questionnaire based on the visual analogue scale (VAS) to assess the pain after 4 hours, 24 hours and 48 hours (7). The VAS consisted of a horizontal line measuring $100 \mathrm{~mm}$ in length where the numerical values were grouped into visual categories. Pain was rated according to 4 four categories: no pain (level 1, 0-24mm), mild pain (level 2, 25-49mm), moderate pain (level 3,50-74mm), and severe pain (level 4,74-100mm) $(19,20)$. The number of analgesics taken was also recorded.

\section{Statistical analysis}

Data were presented as frequency $(\mathrm{N})$ and Percentage $(\%)$ values. Chi-square test used to compare between tested group within each followup periods. Wilcoxon singed rank test used to compare between follow-up periods. Significance level was set at $\mathrm{p} \leq 0.05$. Statistical analysis was performed with IBM ${ }^{\circledR}$ SPSS ${ }^{\circledR}$ (SPSS Inc., IBM Corporation, NY, USA) Statistics Version 24 for Windows.

\section{RESULTS}

Patients' flow diagram is showed in Figure1.

For all evaluated demographic variables (age, tooth type and gender), there was no statistical significant difference between both groups (Table 2). Frequency for the pain scores for the tested groups is presented in Table 1. Pain values between groups were not statistically different for all follow-up periods. The pain score was significantly lower 24 hours and 48 hours after intervention in both groups as compared to values recorded 4 hours after intervention. Table 3 gives a detailed overview of the number of anti-inflammatory tablets taken by the patients in both groups. 


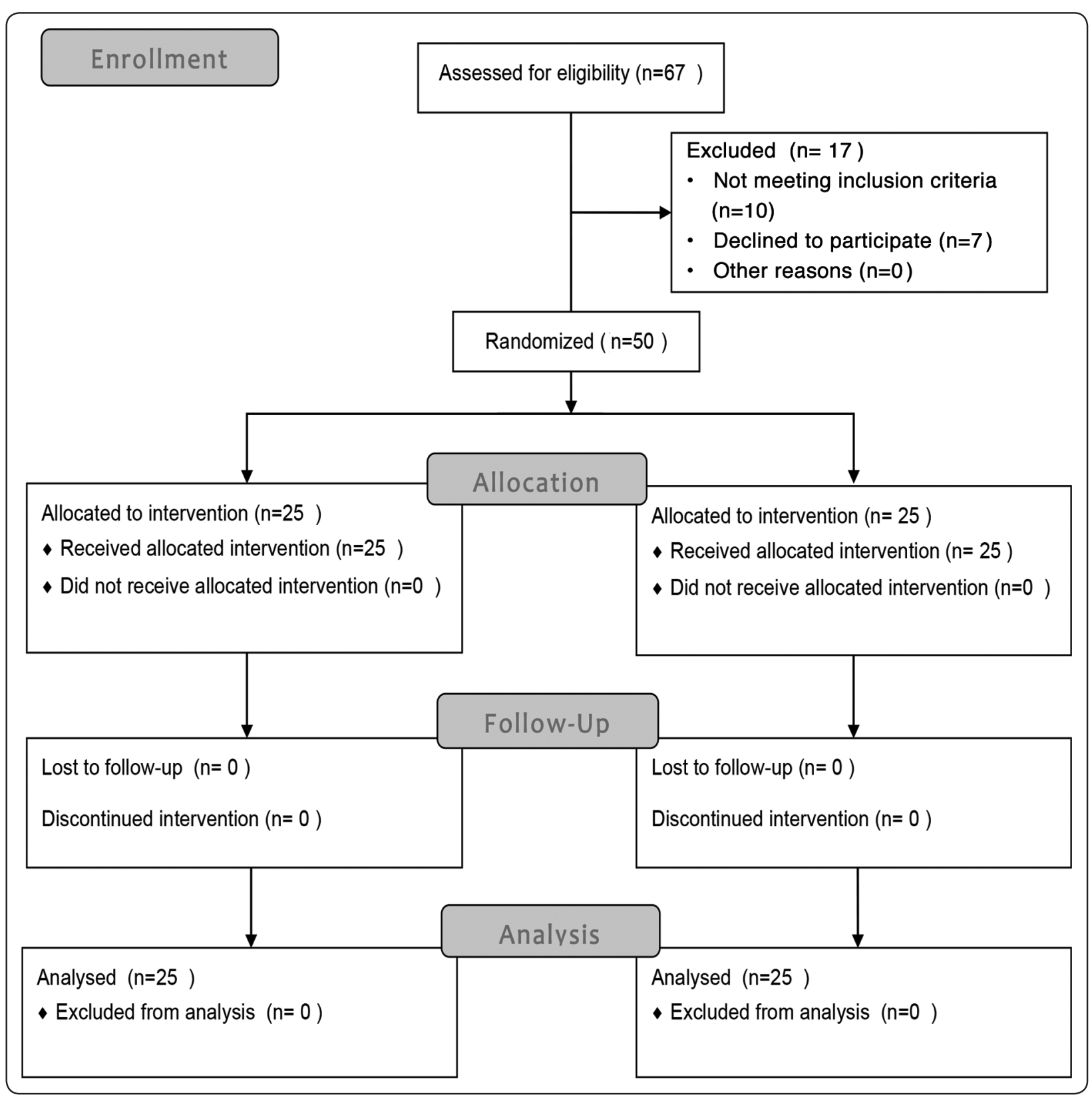

Fig. (1) CONSORT flowchart to depict enrolment of patients, allocation to intervention, and posttreatment pain analysis. 
TABLE (1) Frequency (N) and Percentage (\%) of Pain Score.

\begin{tabular}{|c|c|c|c|c|c|c|}
\hline & & \multicolumn{4}{|c|}{ Group } & \multirow{3}{*}{ p-value } \\
\hline & & \multicolumn{2}{|c|}{ Nano silver } & \multicolumn{2}{|c|}{ NaOCL (Control) } & \\
\hline & & $\mathbf{N}$ & $\%$ & $\mathbf{N}$ & $\%$ & \\
\hline \multirow[t]{5}{*}{$4 \mathrm{hrs}$} & No Pain & 11 & $44.0 \%$ & 10 & $40.0 \%$ & \multirow[t]{5}{*}{$0.921 \mathrm{NS}$} \\
\hline & Mild Pain & 4 & $16.0 \%$ & 4 & $16.0 \%$ & \\
\hline & Moderate Pain & 5 & $20.0 \%$ & 7 & $28.0 \%$ & \\
\hline & Sever Pain & 5 & $20.0 \%$ & 4 & $16.0 \%$ & \\
\hline & Rank & \multicolumn{2}{|c|}{$\mathrm{a}$} & \multicolumn{2}{|c|}{$\mathrm{a}$} & \\
\hline \multirow[t]{5}{*}{24 hrs } & No Pain & 18 & $72.0 \%$ & 20 & $80.0 \%$ & \multirow[t]{5}{*}{$0.117 \mathrm{NS}$} \\
\hline & Mild Pain & 7 & $28.0 \%$ & 2 & $8.0 \%$ & \\
\hline & Moderate Pain & 0 & $0.0 \%$ & 1 & $4.0 \%$ & \\
\hline & Sever Pain & 0 & $0.0 \%$ & 2 & $8.0 \%$ & \\
\hline & Rank & \multicolumn{2}{|c|}{$\mathrm{b}$} & \multicolumn{2}{|c|}{$\mathrm{b}$} & \\
\hline \multirow[t]{5}{*}{$48 \mathrm{hrs}$} & No Pain & 25 & $100.0 \%$ & 25 & $100.0 \%$ & \multirow[t]{5}{*}{$1.00 \mathrm{NS}$} \\
\hline & Mild Pain & 0 & $0.0 \%$ & 0 & $0.0 \%$ & \\
\hline & Moderate Pain & 0 & $0.0 \%$ & 0 & $0.0 \%$ & \\
\hline & Sever Pain & 0 & $0.0 \%$ & 0 & $0.0 \%$ & \\
\hline & Rank & \multicolumn{2}{|c|}{$\mathrm{c}$} & \multicolumn{2}{|c|}{$\mathrm{c}$} & \\
\hline
\end{tabular}

Means with the same letter within each column are not significantly different at $p=0.05$.

*= Significant, $N$ S=Non-Significant

TABLE (2) Frequency (N) and Percentage (\%) of gender and tooth type and age

\begin{tabular}{|c|c|c|c|c|c|c|}
\hline & \multicolumn{4}{|c|}{ Group } & \multirow[t]{3}{*}{ p-value } \\
\hline & & \multicolumn{2}{|c|}{ Nano silver } & \multicolumn{2}{|c|}{ NaOCL (Control) } & \\
\hline & & $\mathbf{N}$ & $\%$ & $\mathbf{N}$ & $\%$ & \\
\hline \multirow[t]{2}{*}{ Gender } & Male & 5 & $20.0 \%$ & 4 & $16.0 \%$ & \multirow[t]{2}{*}{$0.713 \mathrm{NS}$} \\
\hline & Female & 20 & $80.0 \%$ & 21 & $84.0 \%$ & \\
\hline \multirow[t]{3}{*}{ Tooth } & Maxillary Anterior & 10 & $40.0 \%$ & 17 & $68.0 \%$ & \multirow[t]{3}{*}{$0.122 \mathrm{NS}$} \\
\hline & Maxillary Premolar & 4 & $16.0 \%$ & 3 & $12.0 \%$ & \\
\hline & Mandibuler Premolar & 11 & $44.0 \%$ & 5 & $20.0 \%$ & \\
\hline Age (Years) & & 34.08 & 7.86 & 36.80 & 9.32 & $0.270 \mathrm{NS}$ \\
\hline
\end{tabular}

TABLE (3) Frequency (N) and Percentage (\%) of ibuprofen tablets taken postoperatively:

\begin{tabular}{|c|c|c|c|c|c|c|}
\hline & \multicolumn{4}{|c|}{ Group } & \multirow{3}{*}{ p-value } \\
\hline & & \multicolumn{2}{|c|}{ Nano silver } & \multicolumn{2}{|c|}{$\mathrm{NaOCL}$ (Control) } & \\
\hline & & $\mathbf{N}$ & $\%$ & $\mathbf{N}$ & $\%$ & \\
\hline \multirow{5}{*}{$\begin{array}{c}\text { Number of } \\
\text { ibuprofen } \\
\text { tablets taken } \\
\text { postoperatively }\end{array}$} & $\mathbf{0}$ & 0 & $0.0 \%$ & 3 & $12.0 \%$ & \multirow{5}{*}{$0.195 \mathrm{NS}$} \\
\hline & 1 & 13 & $52.0 \%$ & 11 & $44.0 \%$ & \\
\hline & 2 & 11 & $44.0 \%$ & 7 & $28.0 \%$ & \\
\hline & 3 & 1 & $4.0 \%$ & 3 & $12.0 \%$ & \\
\hline & 4 & 0 & $0.0 \%$ & 1 & $4.0 \%$ & \\
\hline
\end{tabular}




\section{DISCUSSION}

In modern endodontics randomized clinical trials provided evidence for the reliability of single visit root canal treatment in asymptomatic necrotic teeth ${ }^{(21,23)}$. All teeth were instrumented and obturated in a single visit to avoid the effect of this variable on postoperative pain. ${ }^{(7)}$. Several systematic reviews and meta-analyses have found either no significant difference or significantly lower postoperative pain following single-visit root canal treatment compared to multiple-visit treatment even in teeth with necrotic pulps ${ }^{(24,25)}$. It was also shown that the incidence of postoperative pain associated with symptomatic teeth was significantly more than asymptomatic teeth ${ }^{(26)}$. Therefore, asymptomatic teeth were only included in the current study to prevent bias and to avoid the influence of preoperative pain being a risk indicator for postoperative pain ${ }^{(27)}$. Several studies showed that there is no the influence of a variety of factors such as age, gender, tooth type, presence of systematic diseases on postoperative pain ${ }^{20,22,23)}$. Therefore, only patients without any contributing history and who did not take analgesics recently were included in this study to avoid any interference of other pain or drug interaction with the pain resulting from the endodontic procedure. Multi-rooted teeth due to its complex morphology is significantly more susceptible to postoperative pain so only single rooted teeth were included in the current study ${ }^{(13)}$. The limitations of the current study are related to small sample size, patient perception of pain, pain measurement and to the methods used to collect the results. Pain perception is a highly subjective and a variable experience affected by many physical and psychological factors. Pain reporting is also difficult as it is influenced by other factors than the experimental methodology such as socioeconomic status of the patient. In the current study, the visual analogue scale (VAS) was used as it is considered to be a valid and reliable instrument for measurement of pain intensity and it was used in other studies with similar objectives ${ }^{(3,7,13)}$.
One of the common causes of postoperative pain is the extrusion of material during treatment or canal obturation ${ }^{(28)}$. Debris extrusion could be a problem with all instrumentation techniques and file systems as all can generate apical extrusion of debris. Hence, the inflammatory reaction could be influenced by the type of file movement and instrument design. Crown-down instrumentation techniques can decrease the positive hydrostatic pressure being directed apically by establishing an adequate escape thus avoiding the passage of irrigating materials in the periapical area ${ }^{(28)}$. Moreover, the measurement of an adequate and reliable working length could be considered mandatory to avoid debris extrusion due to apical instrumentation ${ }^{(29)}$.

There is no general agreement regarding the optimal concentration of $\mathrm{NaOCl}$ for root canal preparation. Higher concentrations of $\mathrm{NaOCl}$ exhibit more cytotoxicity, while providing more tissue-dissolving properties ${ }^{(30)}$. Most studies on postoperative pain have used $2.5-5.25 \%$ or higher concentrations of $\mathrm{NaOCl}{ }^{(31,32)}$. The study by Farzaneh et al ${ }^{(33)}$ showed that patients who received $5.25 \% \mathrm{NaOCl}$ irrigation reported significantly lower pain during the first $72 \mathrm{hr}$ following the treatment compared to those who received $2.5 \%$ $\mathrm{NaOCl}$. The exact reason for less pain when a higher concentration of $\mathrm{NaOCl}$ was used is unclear. However, it is possibly related to the inclusion criteria where only patients with necrotic pulps without periapical pathosis were included. The presence of healthy and intact periapical structures (periodontal ligaments and bone) may prevent extrusion of the irrigant solution as well as debris despite the higher dissolution capacity of $5.25 \%$ $\mathrm{NaOCl}$. Also, the higher dissolution capacity of $5.25 \% \mathrm{NaOCl}$ may dissolve the remaining apical pulp tissues more effectively and therefore preventing the release signaling molecules that may upregulate inflammation in the periapical tissues. This is in agreement with the current study that showed a significant decrease in the pain score for the $\mathrm{NaOCl}$ group after 24 hours followed by significant 
decrease after 48 hours. A systematic review and meta-analysis by Pak \& White ${ }^{(34)}$ showed that during the first 48 hours after root canal treatment, pain felt by the patients significantly decreased. Therefore, some investigations limited their research to the first $48-72$ hours after treatment ${ }^{(35,36)}$. The results showed an insignificant difference between the nano-silver group and the $\mathrm{NaOCl}$ group in pain score along all follow-up periods. For nanosilver group the pain score decreased significantly after 24 hours followed by a significant decrease after 48 hours due the antibacterial effectiveness of nano-silver irrigating solution. By eliminating Gram-negative bacteria that plays an essential role in primary endodontic infections, from the root canal system, postoperative pain could be decreased. Endotoxins play an important role in the initiation and perpetuation of apical periodontitis not by causing a direct cell or tissue damage, but through the stimulation of immune system ${ }^{(37)}$. Wadachi and Hargreaves proposed a mechanism of pain associated with endodontic infections. They demonstrated that trigeminal afferent neurons express the TLR4 and CD14 receptor complex and that LPS activation of TLR-4/CD14 may trigger intracellular signaling cascades, leading to peripheral release of neuropeptides and central nociceptive neurotransmission ${ }^{(38)}$. Postoperative pain with the nano-silver group was related to its cytoxicity to host cells ${ }^{(16,39)}$ and this confirmed that the cytotoxicity of nano-silver is concentration dependent, therefore the concentration of the nanosilver irrigating solution used was $1 \mathrm{mM} \mathrm{Ag} 1+$ $(109 \mu \mathrm{g} / \mathrm{ml})$ to decrease its cytotoxicity.

Analgesics were only prescribed on-demand and not on regular basis as medication may affect the main outcome of the study. Non-steriodal antiinflammatory has been recommended as the first medication of choice for postoperative management after endodontic therapy ${ }^{(40)}$. Therefore, ibuprofen was used in the current study. Our results showed a non-significant difference between both groups in the number of ibuprofen tablets taken postoperatively.
Parirokh et al. ${ }^{(41)}$ reported no significant difference in pain felt by the patients with either regular or on-demand use of ibuprofen following treatment of mandibular molars with irreversible pulpitis. Also the number of analgesics taken by patients who had $5.25 \% \mathrm{NaOCl}$ was significantly lower compared to the ones who had $2.5 \% \mathrm{NaOCl}$ which confirmed lower pain reported by the patients in the $5.25 \%$ $\mathrm{NaOCl}$ group. This is consistent with other studies showing the same results ${ }^{(3,7,20)}$. The current study recommends the use of nano-silver as an adjunct to $\mathrm{NaOCl}$ to improve the antimicrobial efficiency of the used irrigating solution.

In conclusion, both tested irrigants $(5.25 \% \mathrm{NaOCl}$ and $1 \mathrm{mM} \mathrm{Ag} 1+(109 \mu \mathrm{g} / \mathrm{ml})$ nano-silver $)$ were associated with decreased incidence of postoperative pain after single- visit endodontic treatment with necrotic pulps. There was no statistical significant difference between both groups. Further research comparing the postoperative pain experienced after using nano-silver irrigating solution versus sodium hypochlorite in symptomatic necrotic cases is suggested.

\section{ACKNOWLEDGMENT}

The authors deny any conflicts of interest

\section{REFERENCES}

1. Sathorn C, Parashos P, Messer H. The prevalence of postoperative pain and flare-up in single- and multiplevisit endodontic treatment: a systematic review. Int Endod J 2008;41:91-9.

2. Seltzer S. Pain in endodontics. 1986. J Endod 2004; 30:501-3.

3. Bilgili D, Yilmaz S, Dumani A and Yoldas O. Postoperative pain after irrigation with Vibringe versus a conventional needle: a randomized control trial. Int Endod J 2016; 49: 1-7

4. Peters OA, Scho“nenberger K, Laib A. Effects of four NiTi preparation techniques on root canal geometry assessed by micro computed tomography. Int Endod J 2001; 34: 221-30. 
5. Skidmore AE, Bjorndal AM. Root canal morphology of the human mandibular first molar. Oral Surg Oral Med Oral Pathol 1971; 32: 778-84.

6. Wu MK, Wesselink PR. A primary observation on the preparation and obturation of oval canals. Int Endod $\mathrm{J}$ 2001; 34: 137-41.

7. Gondim E Jr, Setzer FC, Dos Carmo CB, Kim S. Postoperative pain after the application of two different irrigation devices in a prospective randomized clinical trial. J Endod. 2010;36:1295-301.

8. Zehnder M. Root canal irrigants. J Endod 2006; 32: 389-98.

9. Shuping GB, Orstavik D, Sigurdsson A, et al. Reduction of intracanal bacteria using nickel-titanium rotary instrumentation and various medications. J Endod 2000;26:751-5.

10. Naenni N, Thoma K, Zehnder M. Soft tissue dissolution capacity of currently used and potential endodontic irrigants. J Endod 2004;30:785-7.

11. Torabinejad M, Shabahang S, Bahjri K. Effect of MTAD on postoperative discomfort: a randomized clinical trial. J Endod. 2005;31:171-6.

12. Kleier DJ, Averbach RE, Mehdipour O. The sodium hypochlorite accident: experience of diplomates of the American Board of Endodontics. J Endod 2008;34:1346-50.

13. Ramamoorthi S, Nivedhitha MS, Divyanand MJ. Comparative evaluation of postoperative pain after using endodontic needle and EndoActivator during root canal irrigation: A randomised controlled trial. Aust Endod J. 2015;41:78-87.

14. Ravishankar Rai V and Jamuna Bai A. Nanoparticles and their potential application as antimicrobials. Science against microbial pathogens: communicating current research and technological advances A. Mendez-Vilas (Ed.) 2011: 197-209.

15. Rai MK, Dille J, Godet S. Synthesis and antibacterial activity of silver nanoparticles against gram-positive and gram-negative bacteria. Nanomedicine 2012; 8: 37-45.

16. Gomes-Filho JE, Silva FO, Watanabe S, et al. Tissue reaction to silver nanoparticles dispersion as an alternative irrigating solution. J Endod 2010; 36: 1698-1702.

17. Wu D, Fan W, Kishen A, Gutman JL, Fan B. Evaluation of the antibacterial efficacy of silver nanoparticles against Enterrococcus faecalis biofilm. J Endod 2014; 40: 285-290.
18. A. Moher D, Hopewell S, Schulz KF, Montori V, Gotzsche PC, Devereaux PJ, et al. CONSORT 2010 explanation and elaboration: updated guidelines for reporting parallel group randomised trials. BMJ. 2010; 340: c869

19. Myles PS, Troedel S, Boquest M, et al. The pain visual analogue scale: is it linear or nonlinear? Anesth Analg1999;89:1517-20.

20. Kherlakian D, Cunha RS, Ehrhardt IC, Zuolo ML, Kishen A, da Silveira Bueno CE. Comparison of the Incidence of Postoperative Pain after Using 2 Reciprocating Systems and a Continuous Rotary System: A Prospective Randomized Clinical Trial. J Endod. 2016 ;42:171-6

21. Pasqualini D, Corbella S, Alovisi M, Taschieri S, Del Fabbro M, Migliaretti G, Carpegna GC, Scotti N, Berutti E. Postoperative quality of life following single-visit root canal treatment performed by rotary or reciprocating instrumentation: a randomized clinical trial. Int Endod J. 2016;49:1030-1039.

22. Shokraneh A, Ajami M, Farhadi N, Hosseini M, Rohani B. Postoperative endodontic pain of three different instrumentation techniques in asymptomatic necrotic mandibular molars with periapical lesion: a prospective, randomized, double-blind clinical trial. Clin Oral Investig. 2017;21:413-418.

23. Relvas JB, Bastos MM, Marques AA, Garrido AD, Sponchiado EC Jr. Assessment of postoperative pain after reciprocating or rotary $\mathrm{NiTi}$ instrumentation of root canals: a randomized, controlled clinical trial. Clin Oral Investig. 2016;20:1987-1993.

24. Su Y, Wang C, Ye L. Healing rate and post-obturation pain of single- versus multiple-visit endodontic treatment for infected root canals: a systematic review. J Endod 2011;37:125-32.

25. Wong AW, Zhang C, Chu CH. A systematic review of nonsurgical single-visit versus multiple-visit endodontic treatment. Clin Cosmet Investig Dent 2014;6:45-56.

26. Applebaum E, Nackley AG, Bair E, Maixner W, Khan AA .Genetic variants in cyclooxygenase-2 contribute to post-treatment pain among endodontic patients. J Endod 2015;41: 1214-8

27. Law AS, Nixdorf DR, Aguirre AM et al. Predicting severe pain after root canal therapy in the National Dental PBRN. National dental PBRN collaborative group. J Dent Res.2015;94: 37S-43S. 
28. Caviedes-Bucheli J, Castellanos F, Vasquez N, Ulate E, Munoz HR. The influence of two reciprocating single-file and two rotary-file systems on the apical extrusion of debris and its biological relationship with symptomatic apical periodontitis. A systematic review and meta-analysis. Int Endod J. 2016;49:255-70.

29. VieyraJP, AcostaJ, MondacaJM.Comparison of working length determination with radiographs and two electronic apex locators. Int Endod J. 2010 Jan;43(1):16-20

30. Goncalves LS, Rodrigues RC, Andrade Junior CV, Soares RG, Vettore MV. The effect of sodium hypochlorite and chlorhexidine as irrigant solutions for root canal disinfection: a systematic review of clinical trials. J Endod 2016;42: 527-32.

31. da Silva EJ, Monteiro MR, Belladonna FG, Almeida JF, DeDeus G, Neves Ade A. Postoperative pain after foraminal instrumentation with a reciprocating system and different irrigating solutions. Braz Dent J 2015 ;26: 216-21.

32. Cruz Junior JA, Coelho MS, Kato AS et al. The effect of foraminal enlargement of necrotic teeth with the Reciproc system on postoperative pain: a prospective and randomized clinical trial. J Endod 2016 ;42: 8-11

33. Farzaneh S, Parirokh M, Nakhaee N, Abbott PV. Effect of two different concentrations of sodium hypochlorite on postoperative pain following single-visit root canal treatment: a triple-blind randomized clinical trial. Int Endod J. 2017;30: 1-10 .
34. Pak JG, White SN. Pain prevalence and severity before, during, and after root canal treatment: a systematic review. J Endod 2011;37: 429-38.

35. Kara Tuncer A, Gerek M. Effect of working length measurement by electronic apex locator or digital radiography on postoperative pain: a randomized clinical trial. J Endod 2014; 40: 38-41.

36. Kandemir Demirci G, Calıskan MK. A prospective randomized comparative study of cold lateral condensation versus core/gutta-percha in teeth with periapical lesions. J Endod 2016; 42: 206-10.

37. Itoh T, Nakamura H, Kishi J, Hayakawa T. The activation of matrix metalloproteinases by a whole cell extract from Prevotella nigrescens. J Endod 2009;35:55-59.

38. Wadachi R, Hargreaves KM. Trigeminal nociceptors express TLR-4 and CD-14: a mechanism for pain due to infection. J Dent Res 2006;85:49-53.

39. Allaker RP. The use of nanoparticles to control oral biofilm formation. J.Dent Res 2010; 89: 1175-1186.

40. Keiser K, Byrne BE. Endodontic pharmacology. In: Hargreaves KM, Cohen S, eds.Pathways of the Pulp, 10th ed. St Louis: Mosby Elsevier; 2011:671-90.

41. Parirokh M, Sadr S, Nakhaee N, Abbott PV, Manochehrifar H. Comparison between prescription of regular or ondemand ibuprofen on postoperative pain after single visit root canal treatment of teeth with irreversible pulpitis $\mathrm{J}$ Endod 2014;40: 151-4. 